\title{
Donde la Arquitectura Habita
}

\author{
Where Architecture Lives
}

\author{
> Gabriela G. Tirado Rueda \\ Universidad de Sonora, México \\ ggtr1986@hotmail.com
}

\begin{abstract}
Educative Project designed for children from ages between 6 to 12 years, focused on develop workshops using a dynamic learning methodology who leads the kids to get familiar with the city and its environment. For this, the intention is to develop their creativeness using elements that stimulate all senses as well as provide the opportunity of imagine and extend their knowledge on the referred subjects; while raise awareness about the respect that they must have on the environment, discovering their capacity to transform their habitat growing as respectful citizens and responsible for the community on which they desire to live.
\end{abstract}

Keywords: Arquitectura; Educación; Psicomotricidad; Talleres para niños; Urbanismo.

What's done to children, they will do to society - Karl Menninger

\section{Introducción}

"Donde la arquitectura habita" es un proyecto educativo que se desarrolla en la ciudad de Hermosillo, situada al noroeste de México.

El autor cuenta con la cooperación y asesoría de profesionistas especializados en las ramas de arquitectura, urbanismo y psicopedagogía.

Una base educativa sólida en las primeras etapas de crecimiento de los seres humanos lleva consigo la estimulación temprana del cerebro, induciendo a los individuos a pensar y actuar de manera lógica y coherente. Para una convivencia social armoniosa, se requiere que los sujetos cuenten con conocimientos básicos de respeto por lo propio, lo ajeno y el medio que los rodea; la calidad de vida de una sociedad será directamente proporcional al grado de educación con el que cuenten sus propios habitantes.

Tomando en cuenta lo anterior, se investigaron los diversos planes de estudio de institutos de educación básica para niños de 6 a 12 años (de carácter público y privado) y los centros de desarrollo infantil que ofrecen cursos independientes en la ciudad, percibiendo que en ninguno de los anteriores se imparten cursos, talleres o clases sobre el desarrollo de la ciudad, o donde se haga mención sobre la educación arquitectónica, urbanismo y/o el desarrollo sustentable.

El propósito del proyecto es desarrollar talleres con una metodología de aprendizaje dinámica que guíe a los infantes a familiarizarse con la ciudad, detonando su lado creativo utilizando elementos que estimulen sus sentidos; de esta manera, al mismo tiempo que se les brinda la oportunidad de imaginar y extender sus conocimientos en los temas referidos, se trata de concientizarlos sobre el respeto que merece el entorno en el que habitan.

Se tiene como objetivo principal desarrollar la capacidad de los niños de percibir, entender y evaluar el medio natural y construido, ya que si desde pequeńos conocen su capacidad de transformar y mejorar la ciudad y el ambiente que los rodea, crecerán siendo ciudadanos más conscientes del entorno en el cual quieren vivir.

Existen antecedentes de programas de arquitectura educativa para nińos en diversos países del mundo, siendo Finlandia y Espańa los principales precursores. Sin embargo, el nivel educativo y carácter cultural de estos países, es diferente al de Latinoamérica; es por eso que se plantea este proyecto adecuado a las necesidades específicas de las ciudades latinas.

\section{Metodología de la Investigación}

Como punto de partida para comenzar la planeación del proyecto, se necesitó delimitar a qué usuarios va dirigido, el método de enseńanza que se pretende utilizar y los materiales de apoyo que servirán a la realización de los talleres.

\section{Definición de usuarios}

Según la psicóloga Diane Papalia en su estudio sobre desarrollo cognoscitivo define que, desde el enfoque piagetano - refiriéndose a la teoría de desarrollo cognitivo del psicólogo suizo Jean Piaget - la etapa denominada "niñez intermedia" también llamada "etapa de las operaciones concretas", que comprende entre los 6 y 12 ańos de edad, es aquella donde los infantes: 
- $\quad$ Pueden entender las relaciones espaciales, tienen habilidad para usar modelos y mapas, recibir y dar instrucciones claras.

- Llevan a cabo la resolución de problemas de manera lógica y concreta.

- Las habilidades de lenguaje y memoria se ven ampliadas.

- Desarrollan el razonamiento moral, pudiendo llevar a cabo juicios morales; el concepto de equidad e igualdad ya es claro en ellos (Papalia, 2005).

Tomando como base el enfoque piagetano se concluye que la etapa denominada 'nińez intermedia', es la indicada para el desarrollo de los talleres porque se pretende que los nińos lleven a cabo actividades prácticas que los conduzcan a razonar y tomar decisiones.

En el caso de realizar los talleres con niños de educación especial, se deberá realizar un plan de trabajo exclusivo para la comprensión y el correcto desarrollo de sus habilidades.

\section{Constructivismo como método de enseñanza}

El método pedagógico que se utilizará para desarrollar los talleres será el constructivismo; éste es un modelo de investigación psicológica y educativa que definido por las teorías de Jean Piaget, Ven Vygotsky, entre otros.

En el aprendizaje constructivista, el alumno genera sus propios objetivos, 'construye' por sí mismo su conocimiento, basando los resultados en el autoestudio y el trabajo generado en equipo. El profesor funge como guía y plantea ideas y retos a los alumnos buscando una asimilación racional en ellos sin darles un resultado final. De esta manera, el alumno aprende utilizando su propia capacidad de lógica dando flexibilidad a que la ruta de descubrimiento sea variable en cada individuo.

Este sistema de aprendizaje conlleva que el alumno no sólo asimile lo que su asesor le indique -como en los métodos tradicionales de enseñanza- si no que despierte en él una inquietud de seguir hilando respuestas, al ser responsable de su propio aprendizaje.

\section{Materiales de apoyo}

El proyecto contempla el uso de materiales de apoyo visual ya que brinda la absorción de información de manera rápida; se contempla el uso de proyección de imágenes, fotografías y videos relacionados con los componentes claves de la ciudad, la interrelación del medio construido y el medio natural, etc., aunados a una explicación verbal para crear un reforzamiento en la enseñanza.

Para las actividades dinámicas se utilizará el uso de materiales cotidianos para efectuar maquetas, planos o dibujos (según dicte el tema del taller), ya que el hecho de manipular conlleva una expansión viso-motora la cual estimula que los niños relacionen dichos bosquejos u objetos con las partes de una ciudad; por ejemplo, un cartón reciclado pasa de ser un objeto de desecho, a ser una maqueta sobre la organización de la ciudad con sus sendas, nodos, barrios, bordes e hitos; elementos principales de una ciudad, definidos por Kevin Lynch en su libro La Imagen de la Ciudad (1984).

\section{Expectativas}

Donde la arquitectura habita, pretende que los nińos que asistan a los talleres, desarrollen una sensibilidad de respeto y cuidado hacia su ciudad, al mismo tiempo que experimentan con su creatividad y aprenden sobre la importancia de la arquitectura y el urbanismo.

Por lo anterior, se cree que si un nińo en edad adecuada es encausado en el conocimiento de estos temas, en un futuro será un ciudadano responsable y participativo en su ciudad. No se pretende que lleguen a ser arquitectos, ingenieros o urbanistas, pero sí que la ciudad cuente con habitantes comprometidos con su entorno.

\section{Metodologia de los Programas de Trabajo}

Para definir los programas de trabajo de los talleres, se consultó la obra Estrategias Psicomotoras (2002) de la psicomotricista Begońa Suárez, cuyo método de trabajo se basa en crear un vínculo entre la sensibilidad artística y expresiva de los niños y el manejo de sus capacidades psicomotrices mediante vivencias (juegos).

De igual manera se utilizan los conceptos básicos de urbanismo, arquitectura, sustentabilidad y funcionamiento de la ciudad para darle el enfoque deseado a los talleres.

La estructura de los programas se conforma de la siguiente manera:

Palabras clave (keywords): Se manejan palabras clave que definan el área con la que se trabajará: creatividad, imaginación, capacidad perceptiva, coordinación, etc.

Nombre del taller: Se pretende que éste sea de fácil reconocimiento y llame la atención de los infantes, mediante el uso de un lenguaje comprensible.

Objetivos: Cada taller lleva objetivos específicos de aprendizaje basados en el eje temático.

Desarrollo: En este punto se lleva a cabo el proceso puntual del taller, para que se lleve a cabo de manera ordenada.

Material de trabajo: Cada vivencia enumera los recursos que serán utilizados, que pueden ser físicos o digitales, según sea el caso.

Observaciones y conclusiones: Se especifica si el objetivo del taller fue cumplido y se documenta con fotografías o videos como soporte del aprendizaje.

Duración del taller: Se indica la duración del taller, para un mejor aprovechamiento del tiempo.

\section{Programas de trabajos}

Para una mejor comprensión del uso de la metodología de los talleres, se detalla la aplicación de ésta en uno específico:

Keywords: Creatividad; Ubicación espacial; Atención; Percepción visual; Proyectar.

Nombre del taller: Dibujemos la Arquitectura

Objetivos:

- Medir el nivel de las habilidades motoras finas (praxias).

- Conocer la percepción que se tiene sobre el medio ambiente construido.

- Desarrollar conocimientos básicos sobre arquitectura y la ciudad.

Desarrollo:

1. Presentación de los alumnos y el instructor.

2. Comentar sobre el tema a tratar.

3. Exponer una presentación explicando conceptos básicos de arquitectura. 
4. Repartir una hoja de papel por niño, para reforzar el aprendizaje obtenido de la presentación y replantear su boceto.

5. Proporcionar crayolas para identificar áreas (zonas ajardinadas, construcciones, circulaciones viales y peatonales).

6. Comentar sobre la vivencia y explicar su dibujo.

7. Ordenar el lugar de trabajo.

\section{Materiales de trabajo:}

- Papel bond tamaño oficio.

- $\quad$ Lápices de grafito del \#2.

- Crayolas de cera no tóxicas.

- Proyector digital y Laptop.

- Presentación del tema en diapositivas.

- Música instrumental.

\section{Observaciones y conclusiones:}

Se desarrollaron dos talleres sobre el tema: el primero que llamaremos 'grupo a', con 6 niños de entre 6 y 9 años; y el segundo 'grupo b', con 6 niños de entre 10 y 12 años.

Al preguntar al 'grupo a' sobre el significado del término 'arquitectura' se obtuvo un desconocimiento general del tema por parte de los participantes.

Se procedió a realizar la presentación visual del tema, explicando el significado de ciudad, sus componentes y cómo la arquitectura se encuentra presente dentro del entorno urbano de manera conjunta con el medio ambiente natural.

$\mathrm{Al}$ realizar los dibujos, en términos generales, los alumnos denotaron un afianzamiento de lo explicado en la presentación, incorporando viviendas, vialidades, banquetas y seńalamientos viales, zonas deportivas, áreas de servicio (gasolinera, hospital, central de policía, recolección de basura, tiendas de autoservicio, etc.), recintos religiosos, zonas educativas, parques infantiles y áreas verdes.

Para finalizar el taller cada niño expuso su dibujo, explicando porqué así era la arquitectura, recalcando que las áreas verdes debían estar presentes para tener una ciudad "sana" al igual que el servicio de recolección de basura.

Con el 'grupo b', se obtuvieron respuestas concretas sobre el significado de la arquitectura. Las áreas dibujadas -además de las señaladas en el 'grupo a'- fueron el aeropuerto, puentes viales y peatonales, ríos y presas. Los espacios y edificios fueron unificados por distribuidores viales, se tomó en cuenta al peatón, fue utilizado el uso de la perspectiva en el dibujo y se realizaron distribuciones de espacios interiores en algunos edificios proyectados.

En ambos grupos se contó con la colaboración y atención de los participantes, y hubo una notoria inquietud por conocer más sobre el tema.

Como apoyo a las observaciones se anexan las Figuras 1 y 2 donde se muestran dos dibujos, de grupo a y otro de grupo b, respectivamente.

Duración del taller: 60 minutos con grupo a; 90 minutos con grupo b.

\section{Conclusión}

La arquitectura y el urbanismo no deben considerarse disciplinas exclusivas de ciertos sectores de la sociedad ya que son componentes principales en el desarrollo de una ciudad; es por esto que el presente trabajo de investigación pretende ampliar el conocimiento sobre estos temas en una porción de la población segregada, que son los niños.

La capacidad de retención con la que se cuenta en la etapa de niñez intermedia da por resultado que, con el apoyo del tutor, los infantes llegan a conceptualizar el espacio urbano construido de manera gráfica y volumétrica, realizando modelos y bocetos donde plasman las cualidades y carencias que perciben en la ciudad, con lo cual además, se consigue que valoren y desarrollen el respeto hacia ese entorno que los rodea.

La calidad e inquietud por conocer más, que presentan los alumnos al realizar las actividades correspondientes a los talleres, nos indica que es posible establecer bases de conocimiento sólidas en ellos, ya que al estimularlos para que ejerciten sus habilidades psicomotoras en conjunto con la capacidad creativa, se les ayuda a razonar y emitir conclusiones objetivas que, se espera en un futuro, los guíe a ser participativos en las decisiones como miembros activos de la sociedad, sin importar si su profesión u oficio esté relacionado de manera directa con el desarrollo de la ciudad.

\section{Referencias}

Craig, G. (1997). Desarrollo Psicológico. México: Prentice-Hall.

De Elizagarate, V. (2008) Marketing de Ciudades: Estrategias para el Desarrollo de Ciudades Atractivas y Competitivas en un Mundo Global. Madrid: Ediciones Pirámide.

Díaz-Guerrero, R. (2003). Psicología del Mexicano: Descubrimiento de la Etnopsicología. México: Trillas.

Flavell, J. H. (1985). El Desarrollo Cognitivo. Madrid: Visor.

Hernández, S. R., Fernández, C. C. y Baptista, L. P. (2003). Metodología de la Investigación. México: McGraw-Hill.

Lynch, Kevin (2001 [1984]) La Imagen de la Ciudad. Barcelona: Gustavo Gili.

Oliveras, Jordi (2000) “Ciudad”. En: Introducción a la Arquitectura. Conceptos Fundamentales. Barcelona: Ediciones UPC.

Papalia, D. (2005). Desarrollo Humano. México: Mcgraw Hill.

Rosi, A. (2013). La Arquitectura de la Ciudad. México: Gustavo Gili

Suárez, B. (2002). Estrategias Psicomotoras. México: Editorial LIMUSA. Vygotsky, L. (1978). Pensamiento y Lenguaje. Madrid: Editorial Paidós
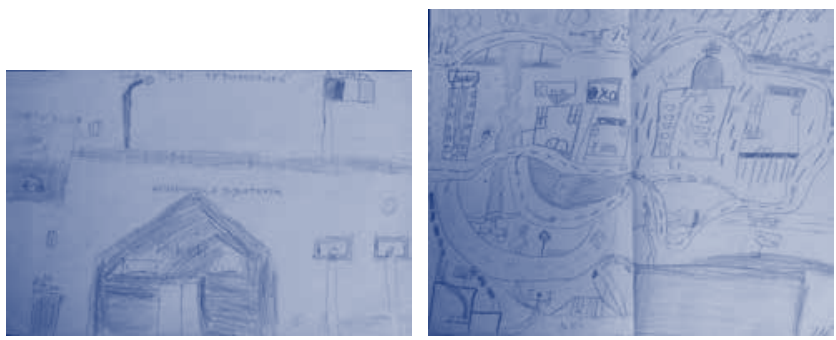

Figura 1: Dibujo sobre arquitectura realizado por Ruben, de 7 años.

Figura 2: Dibujo de la arquitectura de la ciudad. Yahir, 11 años. 